Journal of Porous Materials 12: 323-336, 2005
(c) 2005 Springer Science + Business Media, Inc. Manufactured in The Netherlands.

\title{
Selective Methyl Tert-Butyl Ether Synthesis over Metal Exchanged Pillared Clays
}

\author{
K. MANJU AND S. SUGUNAN* \\ Department of Applied Chemistry, Cochin University of Science and Technology, Kochi-22, India \\ ssg@cusat.ac.in
}

Received August 2, 2004; Revised March 30, 2005

\begin{abstract}
Iron and mixed iron aluminium pillared montmorillonites prepared by partial hydrolysis method was subjected to room temperature exchange with transition metals of the first series. The materials exhibit good structural as well as thermal stability. Exchanged metals were found to be present inside the porous network, in the environs of the pillars. Mixed pillaring resulted in the intercalation of $\mathrm{Al}_{13}$ like polymers in which $\mathrm{Al}$ is partially substituted by Fe. The acidic structure was followed by temperature programmed desorption of ammonia and cumene cracking test reaction. Weak and medium sites overshadow the strong sites in all systems. However, exchange with metals increases the number of strong sites. The prepared materials are efficient catalysts for gas phase MTBE synthesis. The catalytic activity can be well correlated with the total amount of weak and medium acid sites.
\end{abstract}

Keywords: pillared clay, transition metal exchange, acidity, methyl tert-butyl ether

\section{Introduction}

The intercalation of clays with large, oxygen containing cations to produce pillared clays has been investigated for nearly twenty years. Montmorillonite is a common starting material because of its favourable characteristics of expandability, cation exchange capacity and its widespread availability. Many porous compounds have been synthesised with a variety of textural and surface chemical characteristics thereby producing a wide range of adsorption and catalytic applications. These materials result from a two step modification of swelling clay minerals; insertion of polyoxocations into the interlamellar space and stabilisation of the polymeric species by subsequent thermal treatment. Iron is a preferred metal for pillaring since iron pillared clays are cheaper to prepare and would not only have acidic properties but also contain pillars which in themselves would be catalytically active and have redox and magnetic properties [1]. The thermal stabil-

${ }^{*}$ To whom correspondence should be addressed. ity and catalytic properties of iron oxide pillared clays can be improved by incorporating a second component into pillars. Usually, transition metals are deposited on pillared clays by means of ion exchange, incipient wetness or dry impregnation of calcined samples. Copper, vanadium and platinum have been the preferred active phases and to a lesser extent nickel, manganese, cobalt and other elements $[2,3]$.

Combustion of fossil fuels for the purpose of transport and heating contributes significantly to problems like global warming, hazardous carbon monoxide pollution and other toxic pollutants. Due to strong environmental concerns about fuel emissions, use of metal octane enhancers such as tetraethyl lead in gasoline has been phased out in many countries. The addition of fuel oxygenates to gasoline for increased octane number resulted in higher engine efficiency and reduction of polluting components in exhaust, thereby significantly reducing toxic tailpipe pollution. Among many oxygenated compounds, methyl tert butyl ether (MTBE) has been widely utilised as a gasoline additive due to its good antiknocking properties, lower production cost, 
outstanding physical properties such as volatility, miscibility in gasoline and reduction of environmentally hazardous emissions. The current commercial MTBE synthesis is a liquid phase reaction of methanol and isobutene over sulphonated ion exchange resins, mainly Amberlyst 15 or Lewatit SPC 118 (Bayer) at low temperatures $\left(30-100^{\circ} \mathrm{C}\right)$ and moderately high pressures (usually up to 2.0 MPa). Although resin catalysts are very active, they have some major drawbacks like fragility, sensitivity to methanol to isobutene ratios, corrosive problems, loss of acid sites due to leaching and need of large excess of methanol over isobutene necessitating recycle in industrial installations. In addition, deactivated resin catalyst cannot be regenerated and must be properly disposed under current environmental regulations [4]. Use of resin catalysts leads to undesirable bye products like diisobutenes, dimethyl ether etc. Alternate catalysts like zeolites, sulphated zirconia, heteropoly acids and clays have been developed [5-9]. However, a problem concerning MTBE production from isobutene is that the source of isobutene is limited to catalytic cracking and steam cracking fractions of petroleum refining. Another possible source of isobutene is isobutane dehydrogenation [10].

Commercially, MTBE can also be produced by reaction between methanol and $t$-butanol. The obvious advantage of this process is the direct use of $t$-butanol, a by product in a number of reaction processes such as Halcon process (propylene oxide synthesis), where $3.5 \mathrm{~kg}$ of $t$-butanol is produced per $\mathrm{kg}$ of propylene oxide. There are two ways to produce MTBE from $t$ butanol; the indirect and the direct method. In the former reaction, $t$-butanol is dehydrated to isobutene in the first reactor followed by reaction with methanol in the second reactor. In the direct method, MTBE can be produced by reacting $t$-butanol directly with methanol in one reactor in presence of an acid catalyst in which water is also formed as co product. Pillared clays have been suggested as potential catalysts for the reaction because etherification can occur more readily in the inner layer space [11]. In fact pillaring of clay with chlorhydrol plus certain phosphates has led to improved MTBE selectivities [12]. Moreover, the reaction can also be thought as a model reaction for understanding the potential use of clays for etherification reactions. Hence, synthesis of MTBE by direct method was attempted over the prepared metal exchanged iron and iron aluminium mixed pillared systems.

\section{Materials and Methods}

The pillared clays were synthesised by partial hydrolysis of $0.1 \mathrm{M} \mathrm{Fe}\left(\mathrm{NO}_{3}\right)_{3}$ solution by drop wise addition of $0.3 \mathrm{M} \mathrm{Na}_{2} \mathrm{CO}_{3}$ solution under vigorous stirring (for iron aluminium mixed pillaring, equimolar ratios of $\mathrm{Fe}\left(\mathrm{NO}_{3}\right)_{3}$ and $\mathrm{Al}\left(\mathrm{NO}_{3}\right)_{3}$ were taken). $\mathrm{N}_{2}$ gas was bubbled through the solution to remove excess $\mathrm{CO}_{2}$ and aged for $24 \mathrm{~h}$ at room temperature. Intercalation of pillaring species into the clay layers was done by treating the pillaring solution with a previously swollen clay suspension at $80^{\circ} \mathrm{C}[\mathrm{OH} /$ metal ratio, 2 and metal/clay ratio, $20 \mathrm{mmol} / \mathrm{g}$ clay]. The clay after exchange was washed several times with distilled water and filtered. This was dried in air oven at $110^{\circ} \mathrm{C}$ overnight, followed by calcination for $6 \mathrm{~h}$ at $450^{\circ} \mathrm{C}$ in muffle furnace. Exchange with transition metals was done using 0.1 molar aqueous solutions of the corresponding metal nitrate. For exchange with vanadium, requisite amount of ammonium metavanadate was dissolved in oxalic acid. Pillared clays were stirred mechanically with salt solutions for $24 \mathrm{~h}$ at room temperature. The clay after exchange was washed 5-6 times with distilled water. This was filtered and dried in air oven at $110^{\circ} \mathrm{C}$ overnight and calcined for $5 \mathrm{~h}$ at $500^{\circ} \mathrm{C}$. The pillared clays synthesised for the present study are notated as $\mathrm{X} / \mathrm{Fe} \mathrm{PM}$ or $\mathrm{X} / \mathrm{FeAl} \mathrm{PM}$ where $\mathrm{X}$ is the transition metal exchanged.

EDX analysis of the prepared samples was done in a JEOL JSM-840 A (Oxford make model 16211 with a resolution of $1.3 \mathrm{eV}$ ). Samples were prepared by dusting the clay powder onto double sided carbon tape, mounted on a metal stub. The diffractometer traces of the samples were taken in RIGAKU D/MAX-C instrument using $\mathrm{Cu} \mathrm{K} \alpha$ radiation $(\lambda=1.5405 \AA)$. The simultaneous determination of surface areas and pore volumes of the catalyst samples was done on a Micromeritics Gemini analyser. Previously activated samples were degassed at $200^{\circ} \mathrm{C}$ under nitrogen atmosphere for $2 \mathrm{~h}$ and then brought to nitrogen boiling point. The external surface area was determined by $t$-plot method. FTIR spectra of the samples were recorded using a Perkin Elmer RX-1 spectrometer by the $\mathrm{KBr}$ disc method in the range $400-4000 \mathrm{~cm}^{-1}$. NMR spectra of samples were recorded by a 300 DSX Brucker spectrometer with static magnetic field of 8.5T. Shimadzu TGA-50 instrument was used for carrying out thermogravimetric studies. About $10 \mathrm{mg}$ of the sample was heated at a rate of $20^{\circ} \mathrm{C}$ per minute in the temperature range of $50-600^{\circ} \mathrm{C}$. 
Table 1. Elemental composition of the systems.

\begin{tabular}{|c|c|c|c|c|c|c|c|c|}
\hline \multirow[b]{2}{*}{ Catalyst } & \multicolumn{8}{|c|}{ Element $(\%)^{1}$} \\
\hline & $\mathrm{Na}$ & $\mathrm{Mg}$ & $\mathrm{Al}$ & $\mathrm{Si}$ & $\mathrm{K}$ & $\mathrm{Ca}$ & $\mathrm{Fe}$ & $\mathrm{TM}^{2}$ \\
\hline V/Fe PM & 0.29 & 1.38 & 14.09 & 46.96 & 1.11 & 0.41 & 33.43 & 2.33 \\
\hline $\mathrm{Mn} / \mathrm{Fe} \mathrm{PM}$ & 0.31 & 1.52 & 14.71 & 46.85 & 1.07 & 0.44 & 35.1 & 1.19 \\
\hline $\mathrm{Co} / \mathrm{Fe} \mathrm{PM}$ & 0.37 & 1.34 & 14.09 & 46.52 & 1.85 & 0.50 & 33.36 & 1.97 \\
\hline $\mathrm{Ni} / \mathrm{Fe} \mathrm{PM}$ & 0.44 & 1.85 & 14.78 & 47.06 & 1.54 & 0.49 & 33.84 & 1.93 \\
\hline $\mathrm{Cu} / \mathrm{Fe} \mathrm{PM}$ & 0.36 & 1.03 & 14.46 & 47.94 & 1.61 & 0.42 & 32.97 & 1.21 \\
\hline $\mathrm{Zn} / \mathrm{Fe} \mathrm{PM}$ & 0.34 & 1.84 & 14.12 & 47.12 & 1.64 & 0.46 & 31.22 & 2.26 \\
\hline $\mathrm{Fe} P \mathrm{PM}$ & 0.33 & 1.42 & 14.88 & 45.55 & 1.91 & 0.56 & 35.21 & - \\
\hline V/FeAl PM & 0.23 & 1.48 & 20.69 & 56.18 & 1.8 & 0.35 & 17.08 & 1.99 \\
\hline $\mathrm{Mn} / \mathrm{FeAl} \mathrm{PM}$ & 0.21 & 1.58 & 19.95 & 56.07 & 2.19 & 0.39 & 16.9 & 2.51 \\
\hline $\mathrm{Co} / \mathrm{FeAl} \mathrm{PM}$ & 0.22 & 1.59 & 21.29 & 56.0 & 2.02 & 0.41 & 17.01 & 1.26 \\
\hline Ni/FeAl PM & 0.28 & 1.78 & 21.22 & 56.26 & 2.04 & 0.4 & 17.02 & 1.3 \\
\hline $\mathrm{Cu} / \mathrm{Fe} \mathrm{Al} \mathrm{PM}$ & 0.32 & 1.46 & 20.73 & 55.85 & 2.24 & 0.31 & 17.29 & 1.8 \\
\hline $\mathrm{Zn} / \mathrm{FeAl} \mathrm{PM}$ & 0.22 & 1.83 & 19.94 & 55.0 & 1.57 & 0.43 & 16.73 & 3.18 \\
\hline $\mathrm{FeAl} P \mathrm{PM}$ & 0.31 & 1.97 & 21.41 & 56.61 & 2.67 & 0.54 & 17.29 & - \\
\hline M & 2.18 & 2.81 & 17.74 & 56.47 & 4.11 & 5.01 & 11.67 & - \\
\hline
\end{tabular}

${ }^{1}$ As determined by Energy Dispersive X-ray analysis. The reported values are within the error limit of $\pm 5 \%$.

${ }^{2}$ Exchanged transition metal.

Temperature programmed desorption of ammonia was done using a conventional flow type apparatus. Cumene cracking and gas phase MTBE synthesis were carried out at atmospheric pressure in a fixed bed, downflow vertical glass reactor $(1 \mathrm{~cm}$ diameter, $40 \mathrm{~cm}$ length) inside a double zone furnace. $0.5 \mathrm{~g}$ catalyst activated at $500^{\circ} \mathrm{C}$ was immobilised inside the reactor using glass wool, sandwiched between inert silica beads. A thermocouple positioned near the catalyst bed monitored the reaction temperature, regulated using a temperature controller. The reactants were fed into the reactor with the help of a syringe pump at controlled flow rate. The products were collected downstream the reactor in a receiver connected through a water condenser and analysed using Chemito 8610 Gas Chromatograph equipped with Flame Ionisation Detector and appropriate coloumn.

\section{Results and Discussion}

\section{Energy Dispersive X-ray Analysis}

The elemental compositions of the individual systems as obtained from EDX are presented in Table 1. The parent clay has considerable amount of exchangeable cations, viz., $\mathrm{Na}, \mathrm{Mg}, \mathrm{K}$ and $\mathrm{Ca}$. An extreme reduction in the amount of these elements occurs as a result of pillaring with iron and for Fe PM the amount of iron increases by $23.54 \%$. For FeAl PM, Fe and Al content of pillared system increases from the original clay by $5.62 \%$ and $3.67 \%$. Room temperature exchange with transition metals incorporates about $1-3 \%$ of the metals into the pillared system. Vanadium and zinc exchange best with single pillared systems while zinc and manganese is loaded to greater extent in the mixed pillared series.

Increase in iron content with corresponding decrease in the amount of exchangeable cations points to successive replacement of interlamellar cations with stable iron oxide pillars for Fe PM. Insertion of oligomeric species occurs at the expense of exchangeable cations as indicated by marked decrease in the amount of $\mathrm{Na}$, $\mathrm{K}, \mathrm{Mg}$ and $\mathrm{Ca}$.

\section{Surface Area and Pore Volume Measurements}

The surface areas of pillared clays are typically obtained by applying BET equation to the $\mathrm{N}_{2}$ adsorption isotherm. However, in microporous solids like pillared clays where the interlamellar distance is of the order of a few molecular diameters, monolayer formation on clay silicate layers occurs. Thus surface areas approximated by Langmuir equation are reasonable representations of pillared clay surface areas. Hence in 
Table 2. Surface area and pore volume of the systems.

\begin{tabular}{|c|c|c|c|c|c|}
\hline \multirow[b]{2}{*}{ Catalyst } & \multicolumn{4}{|c|}{ Surface Area $\left(\mathrm{m}^{2} \mathrm{~g}^{-1}\right)$} & \multirow{2}{*}{$\begin{array}{c}\text { Pore } \\
\text { volume }^{1} \\
\left(\mathrm{ccg}^{-1}\right)\end{array}$} \\
\hline & BET & Langmuir & Microporous & External & \\
\hline $\mathrm{V} / \mathrm{Fe} \mathrm{PM}$ & 160.7 & 234.2 & 118.2 & 42.5 & 0.1991 \\
\hline $\mathrm{Mn} / \mathrm{Fe} \mathrm{PM}$ & 194.1 & 285.4 & 132.3 & 61.8 & 0.2086 \\
\hline $\mathrm{Co} / \mathrm{Fe} \mathrm{PM}$ & 178.3 & 250.8 & 128.6 & 49.7 & 0.1957 \\
\hline $\mathrm{Ni} / \mathrm{Fe} \mathrm{PM}$ & 164.8 & 226.5 & 116.3 & 48.5 & 0.1920 \\
\hline $\mathrm{Cu} / \mathrm{Fe} \mathrm{PM}$ & 171.2 & 248.2 & 120.9 & 50.3 & 0.1992 \\
\hline $\mathrm{Zn} / \mathrm{Fe} \mathrm{PM}$ & 147.7 & 234.8 & 108.6 & 39.1 & 0.1857 \\
\hline Fe PM & 194.2 & 269.7 & 139.4 & 54.8 & 0.2157 \\
\hline V/FeAl PM & 158.3 & 229.9 & 102.3 & 56.0 & 0.1753 \\
\hline $\mathrm{Mn} / \mathrm{FeAl} \mathrm{PM}$ & 156.0 & 219.2 & 100.7 & 55.3 & 0.1703 \\
\hline $\mathrm{Co} / \mathrm{FeAl} \mathrm{PM}$ & 164.9 & 229.5 & 108.6 & 56.3 & 0.1871 \\
\hline Ni/FeAl PM & 142.2 & 203.9 & 98.5 & 43.7 & 0.1673 \\
\hline $\mathrm{Cu} / \mathrm{FeAl} \mathrm{PM}$ & 144.5 & 207.6 & 95.6 & 48.9 & 0.1658 \\
\hline $\mathrm{Zn} / \mathrm{FeAl} \mathrm{PM}$ & 147.2 & 233.6 & 100.3 & 46.9 & 0.1635 \\
\hline FeAl PM & 170.6 & 253.7 & 114.9 & 55.7 & 0.1894 \\
\hline$M^{2}$ & 14.3 & 27.9 & - & - & 0.0058 \\
\hline
\end{tabular}

${ }^{1}$ Pore volume measured at $0.9976 P / P_{0}$.

${ }^{2}$ Montmorillonite KSF

the present study, BET and Langmuir surface areas of various systems obtained directly are tabulated. The external surface areas were calculated from $t$-plot [13].

The surface areas and pore volumes of the prepared systems are given in Table 2. Montmorillonite has a BET surface area of $14.3 \mathrm{~m}^{2} \mathrm{~g}^{-1}$ and Langmuir surface area of $27.9 \mathrm{~m}^{2} \mathrm{~g}^{-1}$. As a result of pillaring, surface area and pore volume increases drastically. About two third of the surface area can be attributed to microporous surface.Pore volume also increases significantly on pillaring. Transition metal exchange decreases the surface area and pore volume, mainly in external surface. Minimum surface area is exhibited by zinc exchanged system. Decrease in surface area can be roughly correlated to the amount of metal oxide incorporated as obtained from EDX measurements.

Pillaring is the process by which stable metal oxide clusters are incorporated into interlayer space of swellable clays. As a result, a two dimensional porous network is created. Hence, surface area and pore volume increases extensively, especially the microporous surface area. The external surface area in pillared clays arises from mesopores which are mainly interparticle voids. Transition metal exchange deposits the metal oxides inside the porous network and hence the decrease in surface area (especially the external surface) and pore volume.

\section{X-ray Diffraction}

Apart from surface area and pore volume measurements, the easiest way to determine whether pillar intercalation is successful is to record the X-ray diffraction pattern of an oriented film of the product. Pillared clays are semi crystalline in nature. The broad bands obtained in the XRD spectrum, instead of sharp peaks can be attributed to semi crystalline nature of clays. The only data that can be obtained is the $d$ spacing of (001) plane that indicates the extent of propping apart of clay layers. X-ray diffraction peaks shows that long range face to face layer aggregation is present in the pillared samples. Thus, it can be safely commented that it is not an edge to face delaminated clay.

The characteristic $d_{001}$ spacing of montmorillonite increased from $9.8 \AA$ to $19.2 \AA$ and $17.8 \AA$ for $\mathrm{Fe}$ $\mathrm{PM}$ and FeAl PM respectively (Fig. 1). Shifting of $2 \theta$ values clearly suggest expansion of clay layer during pillaring process. Formation of mixed $\mathrm{Al}_{13-x} \mathrm{Fe}_{x}$ pillars, based on the $\mathrm{Fe}$ content of the pillared solids was reported by Bergaya et al. [14]. The $d$ spacing of (001) plane increased from 9.8 to $17.8 \AA$ in the present case indicating the presence of Fe substituted $\mathrm{Al}_{13}$ like polymers. This polymer with structural formula, $\left[\mathrm{AlO}_{4} \mathrm{Al}_{12}(\mathrm{OH})_{24}\left(\mathrm{H}_{2} \mathrm{O}\right)_{12}\right]^{7+}$ is a tri-decamer composed of one aluminium tetrahedra surrounded by 12 aluminium octahedra. It contains four layers of superimposed oxygen atoms needed for expanding clay basal spacings to $18 \AA$.

The effect of exchange with transition metals on the XRD patterns was studied for representative samples.

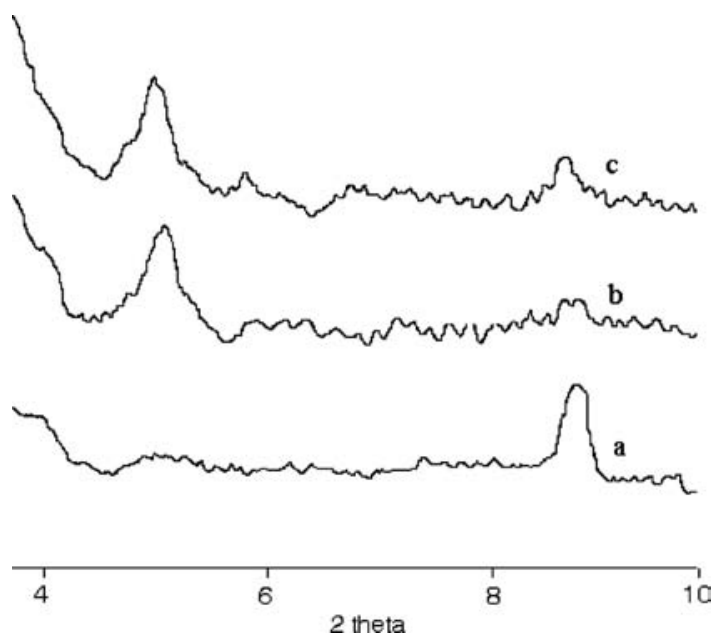

Figure 1. Low angle XRD profile. (a) M (b) Fe PM (c) FeAl PM. 


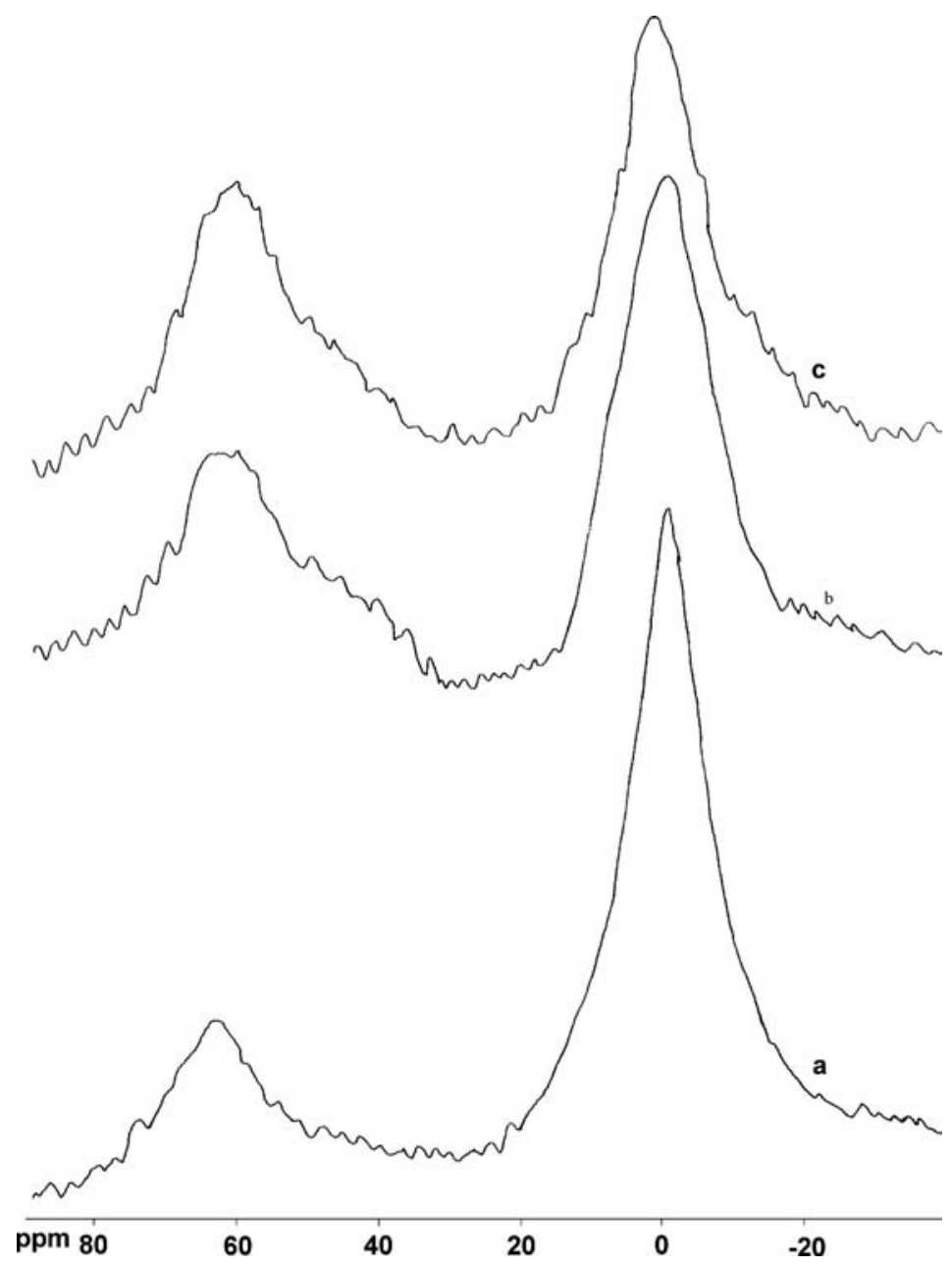

Figure 2. ${ }^{27} \mathrm{Al}$ NMR spectra (a) M (b) Fe PM (c) FeAl PM.

The XRD patterns were exactly identical to that of the parent pillared clay. Thus, it can be concluded that insertion of the second metal after the formation of stable pillars does not destabilise the porous network. Additional peaks corresponding to the exchanged metal oxides were not noticed. This may be due to the diminutive amounts $(1-3 \%)$ of the exchanged metal in these samples.

\section{${ }^{27}$ Al Nuclear Magnetic Resonance Spectroscopy}

The ${ }^{27} \mathrm{Al}$ NMR spectra of the pillared clays are illustrated in Fig. 2. Montmorillonite shows two resonances; one at +1.38 ppm that can be ascribed to octahedral $\mathrm{Al}$ atoms and other at $+66.0 \mathrm{ppm}$ attributable to tetrahedrally coordinated $\mathrm{Al}$ atoms. For Fe PM, in- tensity of ${ }^{27} \mathrm{Al}$ NMR peaks at the octahedral and tetrahedral Al sites are almost similar to that of montmorillonite. Thus, as expected, there is non existence of $\mathrm{Al}$ atoms in the extra framework region. But the peaks are somewhat broader. This can be due to relaxation effects of paramagnetic centres. The ${ }^{27} \mathrm{Al}$ NMR spectrum for FeAl PM shows the $\mathrm{Al}^{I V}$ signature of Keggin cation at $+65.8 \mathrm{ppm}$. Resonance corresponding to octahedral $\mathrm{Al}$ atoms also is shifted to $+1.97 \mathrm{ppm}$. Thus the pillaring solution would be made from these cations in which $\mathrm{Al}^{3+}$ is partially replaced by $\mathrm{Fe}^{3+}$. The nature of substitution is not known, but in view of $\mathrm{Al}$ by $\mathrm{Fe}$ in octahedral layers of micas, it is likely that some of the octahedral $\mathrm{Al}$ atoms in Keggin structure are replaced by Fe atoms [15]. Thus, structure of iron aluminium mixed pillared systems is similar to Al polymeric species and not hydroxy iron oligomers. Here 


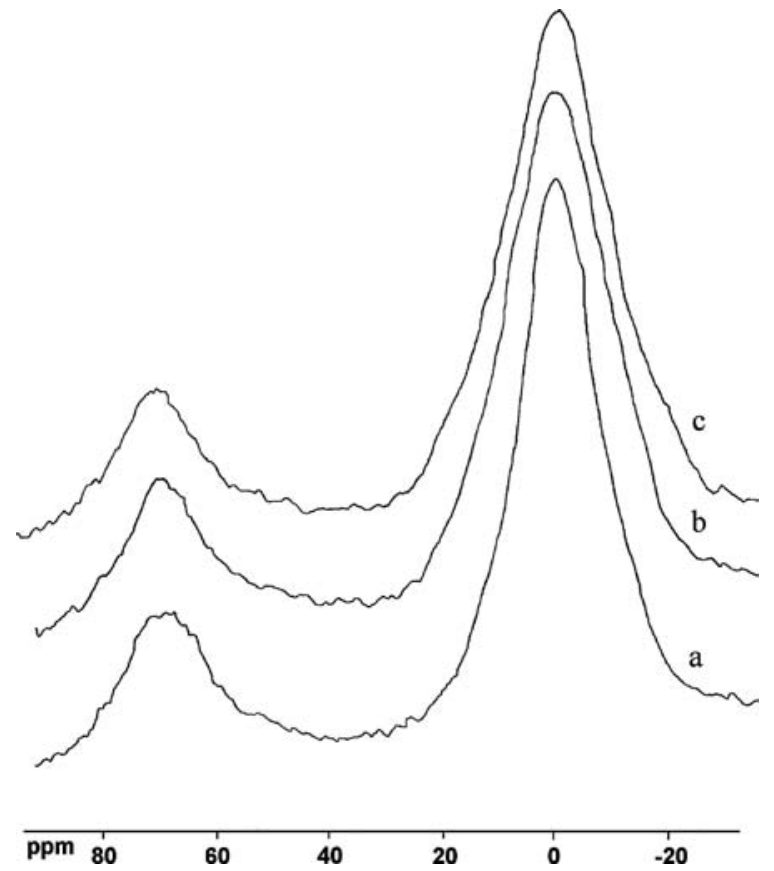

Figure 3. ${ }^{27} \mathrm{Al}$ NMR spectra of exchanged systems (a) Fe PM (b) $\mathrm{Co} / \mathrm{Fe} \mathrm{PM}$ (c) $\mathrm{Cu} / \mathrm{Fe} \mathrm{PM}$.

also, relaxation effects caused by paramagnetic centres are operative. Hence FWHM (full width at half maximum) of the peaks is greater, compared to montmorillonite.

The effect of transition metal exchange on structural stability of pillared clays were examined by taking ${ }^{27} \mathrm{Al}$ NMR spectra of copper and cobalt doped iron pillared systems as representative systems. Figure 3 shows ${ }^{27} \mathrm{Al}$ NMR spectra of Fe PM in comparison with their cobalt and copper exchanged analogues. As a result of exchange with transition metals, peak width as well as peak positions do not vary. This shows that incorporation of transition metals does not affect the structural stability of layers and pillars. Hence ${ }^{27} \mathrm{Al}$ NMR data supports the inference drawn from surface area and pore volume measurements, that metal oxides are incorporated into porous network rather than attached to pillars.

\section{${ }^{29}$ Si Nuclear Magnetic Resonance Spectroscopy}

Figure 4 illustrates the ${ }^{29} \mathrm{Si}$ NMR spectra of montmorillonite and pillared systems. Montmorillonite shows a single resonance centred on $-93 \mathrm{ppm}$. The peak shows a main peak at -93.98 ppm and two shoulder peaks: a

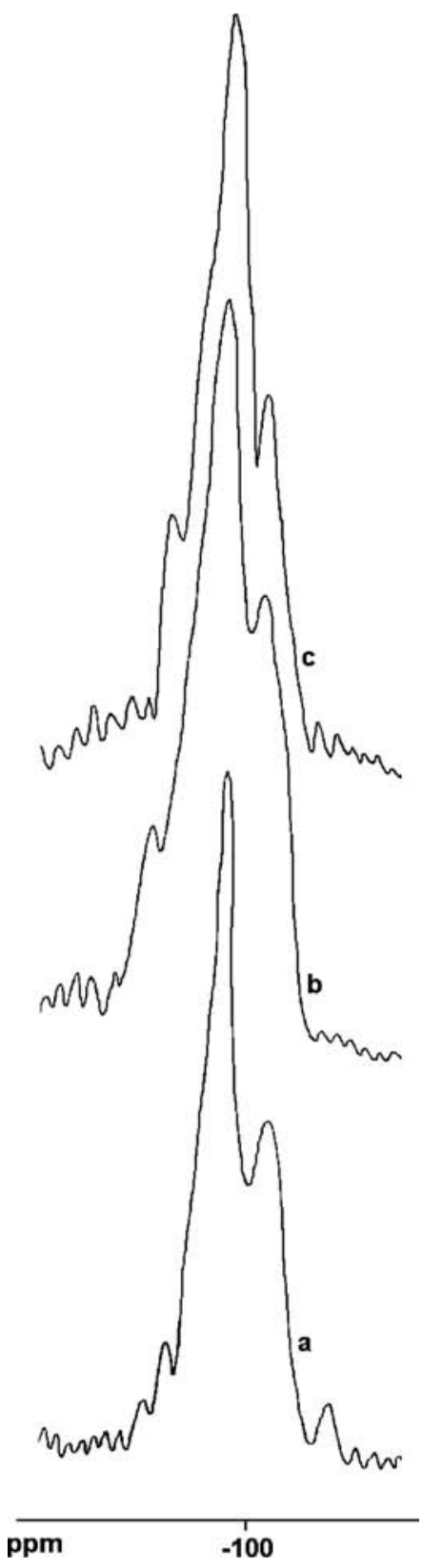

Figure 4. ${ }^{29} \mathrm{Si}$ NMR spectra (a) M (b) Fe PM (c) FeAl PM.

large one at $-104.5 \mathrm{ppm}$ and a diminutive one at -90.3 ppm. The peak at $-93.98 \mathrm{ppm}$ can be attributed to $Q^{3}$ (Si1Al) units representing $\mathrm{Si}(\mathrm{IV})$ atoms linked through oxygen atoms to three other $\mathrm{Si}(\mathrm{IV})$ and to one $\mathrm{Al}(\mathrm{VI})$ (or $\mathrm{Mg}$ ) in the clay octahedral layer. The shoulder peak at $-104.5 \mathrm{ppm}$ can be ascribed to $Q^{3}$ ( $\mathrm{SiOAl}$ ) where $\mathrm{Si}$ is linked to $\mathrm{Si}$ only through oxygens and small peak at $-90.3 \mathrm{ppm}$ is due to $Q^{3}$ (Si2Al). Thus majority of 
Table 3. Distribution of Si atoms to different environments.

\begin{tabular}{lccc}
\hline Catalyst & $\begin{array}{c}Q^{3}(\mathrm{Si0Al}) \\
(\mathrm{ppm})\end{array}$ & $\begin{array}{c}Q^{3}(\mathrm{Si} 1 \mathrm{Al}) \\
(\mathrm{ppm})\end{array}$ & $\begin{array}{c}Q^{3}(\mathrm{Si} 2 \mathrm{Al}) \\
(\mathrm{ppm})\end{array}$ \\
\hline $\mathrm{M}^{1}$ & -90.3 & -93.98 & -104.5 \\
Fe PM & -91.6 & -95.6 & -105.98 \\
Fe Al PM & -91.02 & -94.34 & -105.35 \\
\hline
\end{tabular}

${ }^{1}$ Montmorillonite KSF

the silicon tetrahedra is linked to $3 \mathrm{Si}$ atoms and one $\mathrm{Al}$ atom. A very small portion is linked to $2 \mathrm{Al}$ atoms and $2 \mathrm{Si}$ atoms while a part of Si tetrahedra is linked to $\mathrm{Si}$ atoms alone. This distribution of silicon tetrahedra into various environments is not affected by pillaring. A slight shift in ppm values can be noticed for the pillared samples and this is tabulated in Table 3. From the table it can be inferred that Lowenstein rule is obeyed. Lowenstein rule is the avoidance rule, which states that two tetrahedral Al cannot be next neighbours. Also, the shift in ppm values is in the order Fe PM > FeAl PM. The order is the same as the order of $d$ spacing obtained from X-ray diffraction studies. Thus the shift in ppm, which indicates strain in the local environment of $\mathrm{Si}$ atoms, is proportional to the size of intercalated species. It has been pointed out that inversion of silicon tetrahedra can occur with intercalation of polymeric species in clays like beidellite and saponite where the layer charge is localised in tetrahedral layer [16, 17]. Such an inversion is not anticipated in montmorillonite since layer charge is not localised. ${ }^{29} \mathrm{Si}$ NMR spectra confirm this point since the shift in $\delta$ ppm values is less than 1-2 ppm in all pillared samples. The contributions of different $\mathrm{Si}$ environments also remain the same. This gives confirmation to the nonexistence of chemical bonds between exchanged polymeric species and clay layers. Thus as anticipated, pillaring which is only a cation exchange process does not affect the short range order within clay layers. Had any bond that forms $\mathrm{Al}-\mathrm{O}-\mathrm{Si}$ linkage between the pillars and silicate layers been formed, the spectra would have contained $Q^{3}$ (Si3Al) resonance.

The effect of exchange with transition metals on the structural stability of clay as well as pillaring process was exposed by taking the ${ }^{29} \mathrm{Si}$ NMR spectra of two of the exchanged systems of Fe PM, viz., cobalt and zinc exchanged systems. The spectra are depicted in Fig. 5. From the figure, it can be inferred that $\delta$ ppm values do not alter much as a result of exchange with transition metals. Thus incorporation of transition metals on $\mathrm{Fe}$ $\mathrm{PM}$ does not alter the local environment of Si atoms.

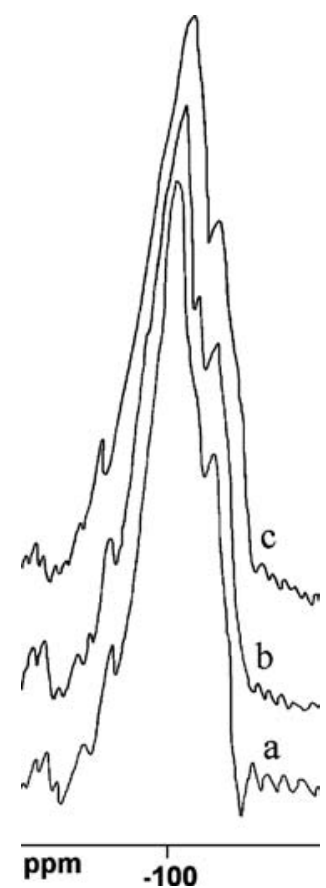

Figure 5. ${ }^{29} \mathrm{Si}$ NMR spectra of exchanged systems (a) Fe PM (b) $\mathrm{Co} / \mathrm{Fe} \mathrm{PM}$ (c) $\mathrm{Cu} / \mathrm{Fe} \mathrm{PM}$.

Hence, it can be inferred that metal oxides are not in the immediate environment of Si layer. They may be present in the porous network of the pillared system.

\section{Acidity of Pillared Clays}

Acidity of pillared clays comes from at least three sources: the original clay, the pillaring cation and binding between clay and pillar [18]. The generally accepted view of acidity of pillared clays is that Lewis sites are mainly resident on metal oxide pillars whereas Brönsted acid sites are associated with structural $\mathrm{OH}$ groups present on the layers of host clay [19]. Pillaring process releases $\mathrm{Na}^{+}$ions from blocked six member silicate rings, creating many accessible structural $\mathrm{OH}$ groups and possible Brönsted sites, which are accessible to probe molecules [20]. The number of Brönsted acid sites decreases with increase in temperature and these sites are practically lost at temperatures above $500^{\circ} \mathrm{C}$. Protons from different sources may be at the origin of acidity of pillared clays. The water molecules belonging to the hydration shell of charge balancing cations are submitted to a strong electrical polarising field and therefore have a degree of dissociation several orders of magnitude larger than liquid water. 
Water molecules hydrating the pillars are then a potential source of acidity whereas it is known that hydroxyl groups of clay octahedral layer do not contribute to acidity.

\section{Temperature Programmed Desorption of Ammonia}

Ammonia is an excellent probe molecule for testing acidic properties of solid catalysts as its strong basicity and small molecular size allow detection of acidic sites located in very narrow pores also. Ammonia adsorption on pillared clays can be physical $\left(\Delta H \approx 13 \mathrm{Kcalmol}^{-1}\right)$ or chemical $(\Delta H \approx 33$ $\mathrm{Kcalmol}^{-1}$ ) type. Acid site distribution profiles show the presence of weak (ammonia desorbed between 35$\left.200^{\circ} \mathrm{C}\right)$, medium $\left(201-400^{\circ} \mathrm{C}\right)$ and strong $\left(401-600^{\circ} \mathrm{C}\right)$ acid sites. The acid site distribution at various temperatures has been calculated as functions of mass of the sample as well as BET surface area (Tables 4 and 5). The former expression helps in quantifying acid sites per gram of clay while the latter helps in understanding the acidic structure of catalysts as a surface property which can be helpful in understanding reaction pathways for acid catalysed reactions.

The tables reveal that in all the prepared systems weak and medium acid sites overshadow the strong sites. V, Mn, Ni and $\mathrm{Cu}$ exchange increases the amount of total acid sites, particularly the strong sites. In the mixed pillared series also, FeAl PM desorbs consider-

Table 4. Acid site distribution/mass of the prepared catalysts.

\begin{tabular}{lcccc}
\hline Catalyst & $\begin{array}{c}\text { Weak } \\
\left(35-200^{\circ} \mathrm{C}\right)\end{array}$ & $\begin{array}{c}\text { Medium } \\
\left(201-400^{\circ} \mathrm{C}\right)\end{array}$ & $\begin{array}{c}\text { Strong } \\
\left(401-600^{\circ} \mathrm{C}\right)\end{array}$ & $\begin{array}{c}\text { Cumulative } \\
\left(\mathrm{mmolg}^{-1}\right)\end{array}$ \\
\hline $\mathrm{V} / \mathrm{Fe} \mathrm{PM}$ & 0.722 & 0.159 & 0.088 & 1.068 \\
$\mathrm{Mn} / \mathrm{Fe} \mathrm{PM}$ & 0.715 & 0.311 & 0.182 & 1.208 \\
$\mathrm{Co} / \mathrm{Fe} \mathrm{PM}$ & 0.420 & 0.191 & 0.057 & 0.688 \\
$\mathrm{Ni} / \mathrm{Fe} \mathrm{PM}$ & 0.997 & 0.350 & 0.258 & 1.505 \\
$\mathrm{Cu} / \mathrm{Fe} \mathrm{PM}$ & 0.696 & 0.287 & 0.153 & 1.136 \\
$\mathrm{Zn} / \mathrm{Fe} \mathrm{PM}$ & 0.592 & 0.112 & 0.080 & 0.784 \\
$\mathrm{Fe} \mathrm{PM}$ & 0.48 & 0.354 & 0.084 & 0.918 \\
$\mathrm{~V} / \mathrm{FeAl} \mathrm{PM}$ & 0.844 & 0.382 & 0.202 & 1.428 \\
$\mathrm{Mn} / \mathrm{FeAl} \mathrm{PM}$ & 0.637 & 0.246 & 0.191 & 1.074 \\
$\mathrm{Co} / \mathrm{FeAl} \mathrm{PM}$ & 1.401 & 0.440 & 0.147 & 1.988 \\
$\mathrm{Ni} / \mathrm{FeAl} \mathrm{PM}$ & 0.524 & 0.224 & 0.299 & 1.047 \\
$\mathrm{Cu} / \mathrm{FeAl} \mathrm{PM}$ & 0.413 & 0.159 & 0.050 & 0.627 \\
$\mathrm{Zn} / \mathrm{FeAl} \mathrm{PM}$ & 0.449 & 0.163 & 0.112 & 0.724 \\
$\mathrm{FeAl} \mathrm{PM}$ & 0.473 & 0.161 & 0.048 & 0.682 \\
\hline
\end{tabular}

Table 5. Acid site distribution/surface area of the catalysts.

\begin{tabular}{lcccc}
\hline Catalyst & $\begin{array}{c}\text { Weak } \\
\left(35-200^{\circ} \mathrm{C}\right)\end{array}$ & $\begin{array}{c}\text { Medium } \\
\left(201-400^{\circ} \mathrm{C}\right)\end{array}$ & $\begin{array}{c}\text { Strong } \\
\left(401-600^{\circ} \mathrm{C}\right)\end{array}$ & $\begin{array}{c}\text { Cumulative } \\
\times 10^{-3}\end{array}$ \\
$\left(\mathrm{mmolm}^{-2}\right)$
\end{tabular}

able amount of ammonia in the weak and medium regions and nominal acidity in strong acid region. Transition metal exchange increases the acidity in all regions especially acidity in strong acid region. V/FeAl PM and $\mathrm{Co} / \mathrm{FeAl} \mathrm{PM}$ exhibits maximum acidity in the series owing to increased concentration of weak acid sites. But, Ni/FeAl PM displays exceptionally high acidity in strong acid region.

$\mathrm{NH}_{3}$-TPD method lacks in discriminating the type of acid sites (Brönsted and Lewis). However it is generally accepted that evacuation of ammonia adsorbed at $400^{\circ} \mathrm{C}$ removes most of the Brönsted acid sites [21]. For pillared clays, it has been documented that ammonia adsorbs in Brönsted sites at temperatures around $250^{\circ} \mathrm{C}$ [22]. Again, it is implied that coordinatively bound ammonia on Lewis site can be desorbed only at high temperatures and hence acidity in strong region can be correlated to the amount of Lewis sites. In pillared clays, Lewis acidity is considered to originate from pillars where as Brönsted acidity arises from structural framework of aluminosilicates. Pore volume values indicate presence of exchanged cations inside the porous network. Hence, increase in number of strong sites can be attributed to contribution of these cations in pillars. This is substantiated by the fact that amount of medium acid sites (correlated to Brönsted acidity), arising from structural framework decreases as a result of transition metal exchange. This may be due to shielding of these sites by the deposition of metals in the pores, near the structural framework. 
Comparison of data in the two tables discloses that acidity is dependant on the surface area in microporous solids. This is most pronounced for $\mathrm{Cu} / \mathrm{Fe} \mathrm{PM}$ and $\mathrm{Zn} / \mathrm{Fe}$ PM. These systems due to the low surface area exhibit higher amounts of acid sites/surface area. This can be highly significant in surface catalysed reactions.

\section{Cumene Cracking Test Reaction}

Cumene is a conventional model compound for testing the catalytic activity since it undergoes diverse reactions over different types of acid sites. Major reactions taking place during cracking of cumene are dealkylation or cracking to benzene and propene and dehydrogenation to $\alpha$-methyl styrene. Small amounts of ethylbenzene and toluene can be formed by cracking of side chain, which on dehydrogenation gives styrene. Cracking of cumene is generally attributed to Brönsted acid sites by carbonium ion mechanism whereas $\alpha$-methyl styrene is formed on Lewis acid sites $[23,24]$.

The catalytic performance of prepared materials for the reaction and the effect of transition metal exchange under optimised conditions are given in Table 6. Ethyl-

Table 6. Catalytic activity of various systems towards cumene cracking.

\begin{tabular}{lcccc}
\hline & & \multicolumn{2}{c}{ Selectivity (\%) } & \\
\cline { 3 - 4 } Catalyst & Conversion (\%) & $\begin{array}{c}\alpha \text {-methyl } \\
\text { styrene }\end{array}$ & $\begin{array}{c}\text { Dealkylation } \\
\text { products }^{1}\end{array}$ & $\begin{array}{c}\text { Lewis/ } \\
\text { Brönsted }^{2}\end{array}$ \\
\hline V/Fe PM & 29.8 & 53.2 & 46.8 & 1.15 \\
Mn/Fe PM & 30.2 & 58.9 & 41.1 & 1.43 \\
Co/Fe PM & 21.8 & 59.7 & 40.3 & 1.48 \\
Ni/Fe PM & 31.7 & 64.7 & 35.3 & 1.83 \\
Cu/Fe PM & 28.9 & 60.0 & 40.0 & 1.5 \\
Zn/Fe PM & 24.5 & 48.2 & 51.8 & 0.94 \\
Fe PM & 25.6 & 58.3 & 42.7 & 1.37 \\
V/FeAl PM & 22.8 & 54.3 & 45.7 & 1.19 \\
Mn/FeAl PM & 22.5 & 53.2 & 46.8 & 1.14 \\
Co/FeAl PM & 32.5 & 54.2 & 45.8 & 1.18 \\
Ni/FeAl PM & 28.9 & 60.7 & 39.3 & 1.54 \\
Cu/FeAl PM & 19.5 & 50.2 & 49.8 & 1.0 \\
Zn/FeAl PM & 21.1 & 53.3 & 46.7 & 1.14 \\
FeAl PM & 20.7 & 62.7 & 36.3 & 1.73 \\
\hline
\end{tabular}

Temperature $-400^{\circ} \mathrm{C}, \mathrm{WHSV}-7 \mathrm{~h}^{-1}$, time on stream $-2 \mathrm{~h}$.

${ }^{1}$ Benzene, toluene, ethyl benzene.

${ }^{2}$ Ratio of $\alpha$-methyl styrene and dealkylated products selectivity. benzene and styrene appeared in minor quantities and in some cases toluene also was detected. All the dealkylated products are bannered together and Lewis to Brönsted ratio gives the ratio between the dehydrogenated and cracked products. Iron pillared clay shows very good activity towards the reaction with high selectivity towards $\alpha$-methyl styrene. Lewis/Brönsted acid ratio is 1.37 for Fe PM. Exchange with transition metals increases the activity except for $\mathrm{Co} / \mathrm{Fe} \mathrm{PM}$ and $\mathrm{Zn} / \mathrm{Fe}$ PM. FeAl PM shows conversion of $20.7 \%$ with a selectivity of $62.7 \%$ for $\alpha$-methyl styrene. Here also, metal exchange decreases the dehydrogenation activity with a concomitant decrease in catalytic activity. The high selectivity for the dehydrogenated product can be attributed to the effective pillaring. It has been well documented that the activity for cumene cracking reaction can be correlated to the total acidity of the catalyst. Also dehydrogenation to $\alpha$-methyl styrene occurs over Lewis acid sites and cracking over Brönsted acid sites. The low activity of $\mathrm{Zn} / \mathrm{Fe}$ PM can be attributed to the higher amount of exchanged zinc as suggested by EDX and surface area measurements. NMR spectroscopy evidences the exchanged metal to be present inside the porous network thus reducing the accessibility to Lewis acid sites, which are resident mainly in the pillars.

\section{Catalytic Activity of Various Systems Towards MTBE Synthesis}

A comparative evaluation of the catalytic activity of prepared pillared clay systems at standard conditions for vapour phase MTBE synthesis is given in Table 7. Fe PM converts $26.5 \%$ of $t$-butyl alcohol in the specified reaction conditions. Exchange with transition metals increases the activity considerably. Thus, $\mathrm{Co} / \mathrm{Fe} \mathrm{PM}$ shows the maximum activity of $93.5 \%$. Exclusive formation of MTBE is observed with all catalytic systems. In the mixed pillared series, FeAl PM shows mediocre activity of $24.8 \%$ with $100 \%$ selectivity for MTBE. Transition metal exchange increases the activity greatly while selectivity remains the same.

From the table, it can be concluded that the prepared systems are efficient catalysts for gas phase synthesis of MTBE. The higher efficiency can be attributed to co-ordinately unsaturated nature of $\mathrm{Fe}$ in the pillars, facilitating nucleophilic attack of isobutyl carbonium ion on methanol. The diffusion rate of MTBE could depend on the porous network and fine pores seem to fill the effective role of diffusion in 
Table 7. Activity of the systems towards MTBE synthesis.

\begin{tabular}{lcc}
\hline Catalyst & Conversion $(\%)^{1}$ & Selectivity $(\%)^{2}$ \\
\hline V/Fe PM & 66.5 & 100 \\
$\mathrm{Mn} / \mathrm{Fe} \mathrm{PM}$ & 79.5 & 100 \\
$\mathrm{Ni} / \mathrm{Fe} \mathrm{PM}$ & 53.1 & 100 \\
$\mathrm{Co} / \mathrm{Fe} \mathrm{PM}$ & 93.5 & 100 \\
$\mathrm{Cu} / \mathrm{Fe} \mathrm{PM}$ & 52.1 & 100 \\
$\mathrm{Zn} / \mathrm{Fe} \mathrm{PM}$ & 36.3 & 100 \\
$\mathrm{Fe} \mathrm{PM}$ & 26.5 & 100 \\
$\mathrm{~V} / \mathrm{FeAl} \mathrm{PM}$ & 69.5 & 100 \\
$\mathrm{Mn} / \mathrm{FeAl} \mathrm{PM}$ & 64.1 & 100 \\
$\mathrm{Ni} / \mathrm{FeAl} \mathrm{PM}$ & 79.7 & 100 \\
$\mathrm{Co} / \mathrm{FeAl} \mathrm{PM}$ & 78.8 & 100 \\
$\mathrm{Cu} / \mathrm{FeAl} \mathrm{PM}$ & 42.4 & 100 \\
$\mathrm{Zn} / \mathrm{FeAl} \mathrm{PM}$ & 49.8 & 100 \\
$\mathrm{FeAl} \mathrm{PM}$ & 24.8 & 100 \\
\hline $\mathrm{Me}$ & &
\end{tabular}

Methanol/tert-butyl alcohol-10, temperature- $180^{\circ} \mathrm{C}, \mathrm{WHSV}-$ $2.4 \mathrm{~h}^{-1}$, TOS $-2 \mathrm{~h}$.

${ }^{1}$ Total percentage of $t$-butyl alcohol transformed.

${ }^{2}$ Selectivity to MTBE.

mesoporous, shape selective catalysts like zeolites [25]. Thus the high selectivity in clay catalysts also can be attributed to the fine two dimensional porous structure.

The rate of etherification reaction has been reported to be dependant on the Brönsted acidity of catalyst

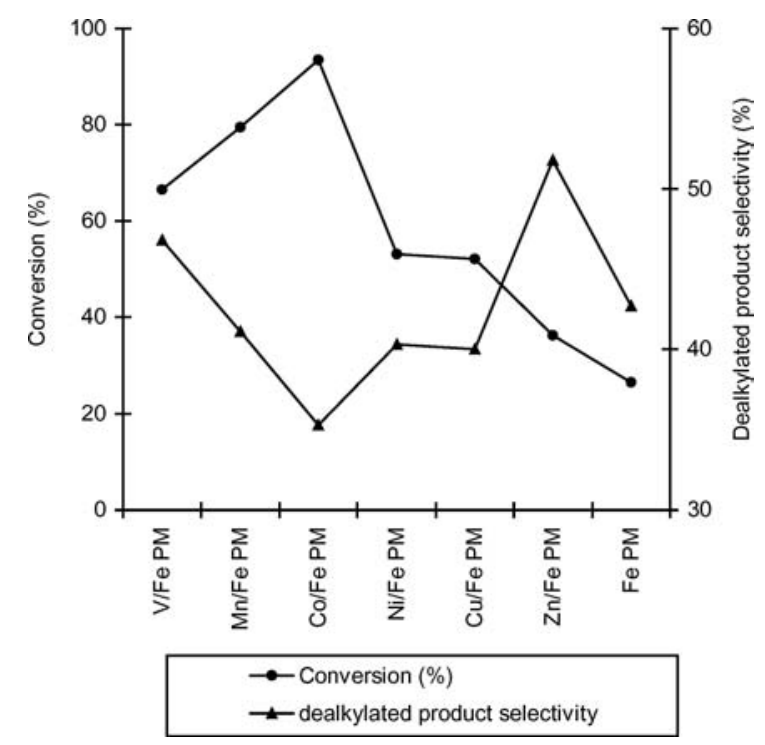

Figure 6. Dependence of catalytic activity for MTBE synthesis on dealkylated product selectivity for iron pillared systems.
$[10,25]$. Hence, an effort was made to correlate activities with Brönsted acidity as obtained from cumene cracking test reaction (Figs. 6 and 8). A rough correlation between the two parameters can be obtained from the figures. A slight discrepancy occurs at Ni/Fe PM. The system should have been more active for the reaction, considering the surface acidity. The catalytic performance of various samples is also correlated with the total amount of weak and medium acid sites obtained from temperature programmed desorption of ammonia (ammonia desorbed in the temperature range of

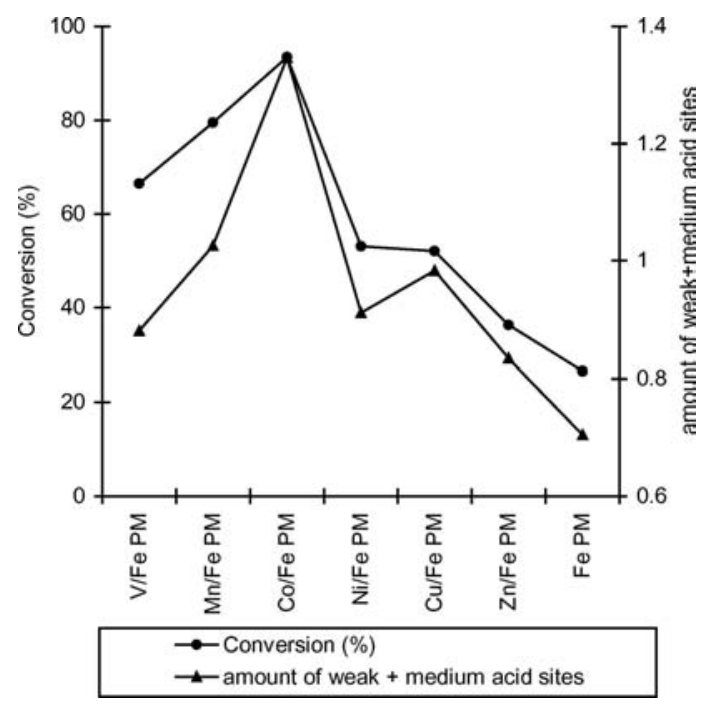

Figure 7. Dependence of catalytic activity for MTBE synthesis on the amount of weak + medium acid sites for iron pillared systems.

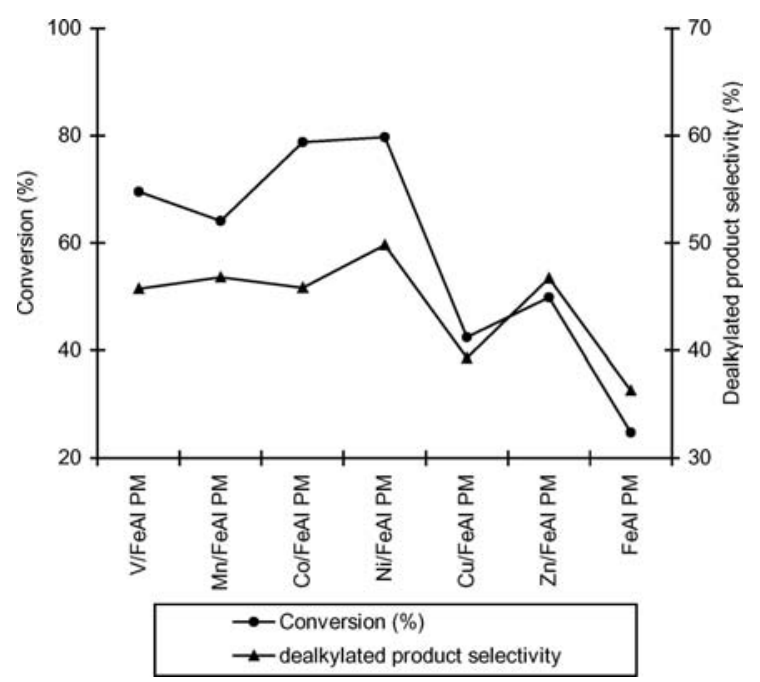

Figure 8. Dependence of catalytic activity for MTBE synthesis on dealkylated product selectivity for mixed pillared systems. 


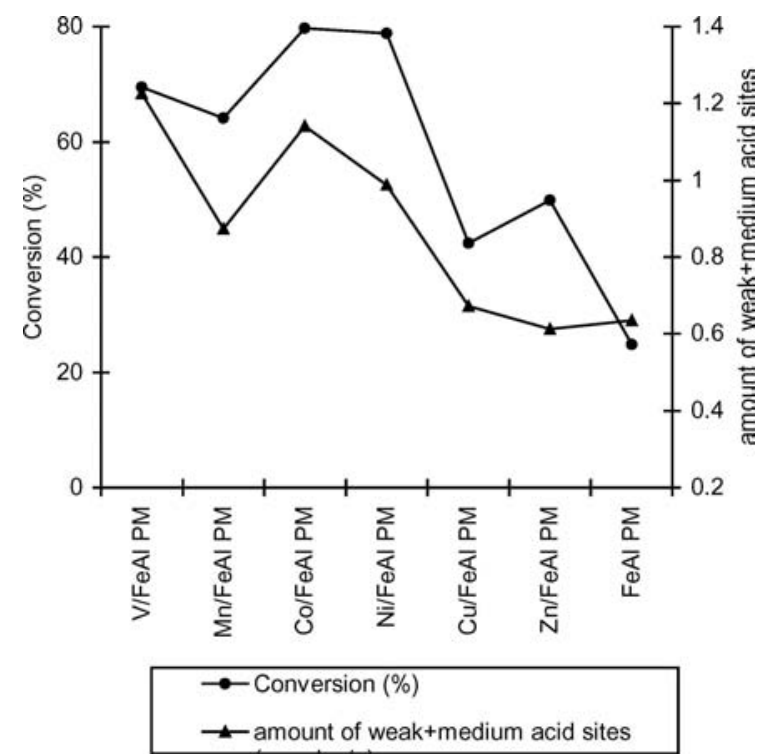

Figure 9. Dependence of catalytic activity for MTBE synthesis on the amount of weak + medium acid sites for mixed pillared systems.

$100-400^{\circ} \mathrm{C}$ ). Figures 7 and 9 show that activity of the prepared catalysts for gas phase MTBE synthesis can be correlated well with the total amount of weak and medium acid sites. The high activity of $\mathrm{Co} / \mathrm{Fe} \mathrm{PM}$ is due to larger amount of weak and medium acid sites. Thus, it can be concluded that gas phase etherification of methanol with $t$-butanol occurs over weak and medium acid sites.

\section{Effect of Reaction Variables}

Gas phase MTBE synthesis by direct method is highly sensitive to reaction conditions. The influence of reaction variables like temperature, molar ratio, weight

Table 8. Effect of temperature.

\begin{tabular}{lcc}
\hline Temperature $\left({ }^{\circ} \mathrm{C}\right)$ & Conversion $(\%)^{1}$ & Selectivity $(\%)^{2}$ \\
\hline 110 & 14.6 & 100 \\
130 & 51.6 & 100 \\
150 & 62.3 & 100 \\
170 & 79.6 & 100 \\
180 & 93.5 & 100 \\
190 & 78.9 & 100 \\
\hline
\end{tabular}

Methanol/tert-butyl alcohol-10, WHSV-2.4 $\mathrm{h}^{-1}$, TOS $-2 \mathrm{~h}$.

${ }^{1}$ Total percentage of $t$-butyl alcohol transformed.

${ }^{2}$ Selectivity to MTBE.
Table 9. Effect of molar ratio.

\begin{tabular}{lcc}
\hline Methanol: TBA & Conversion $(\%)^{1}$ & Selectivity $(\%)^{2}$ \\
\hline $1: 1$ & 14.8 & 100 \\
$2: 1$ & 36.5 & 100 \\
$5: 1$ & 56.8 & 100 \\
$10: 1$ & 93.5 & 100 \\
\hline
\end{tabular}

Temperature $-180^{\circ} \mathrm{C}$, WHSV $-2.4 \mathrm{~h}^{-1}$, TOS $-2 \mathrm{~h}$.

${ }^{1}$ Total percentage of $t$-butyl alcohol transformed.

${ }^{2}$ Selectivity to MTBE.

Table 10. Effect of weight hourly space velocity.

\begin{tabular}{lcc}
\hline WHSV $\left(\mathrm{h}^{-1}\right)$ & Conversion $(\%)^{1}$ & Selectivity $(\%)^{2}$ \\
\hline 1.6 & 98.9 & 100 \\
2.4 & 93.5 & 100 \\
4.0 & 44.9 & 100 \\
5.5 & 43.8 & 100
\end{tabular}

Methanol/tert-butyl alcohol-10, Temperature- $180^{\circ} \mathrm{C}$, TOS $-2 \mathrm{~h}$.

${ }^{1}$ Total percentage of $t$-butyl alcohol transformed.

${ }^{2}$ Selectivity to MTBE.

hourly space velocity and time on stream on the catalytic activity was probed out by taking $\mathrm{Co} / \mathrm{Fe} \mathrm{PM}$ as reference catalyst. Table 9 illustrates the influence of temperature on the reaction in the range of $110-190^{\circ} \mathrm{C}$. Temperature plays a decisive role in MTBE synthesis. A notable increase in $t$-butanol conversion is observed up to $180^{\circ} \mathrm{C}$ followed by decay at higher temperatures. However, deviation from $100 \%$ selectivity to MTBE was not observed even at high temperatures. The decay in reaction rate above $180^{\circ} \mathrm{C}$ can be attributed to extensive dehydration of $t$-butanol which results in decreased amounts of $t$-butanol. Higher reaction temperatures also lead to side reactions producing hydrocarbons and other oxygenates [25].

Methanol is used as both reactant and solvent and hence its amount plays an important role in the reaction. The observations of the study on reactant molar ratio are presented in Table 10. The data shows that increase in methanol increases the activity of catalyst. With an equimolar mixture of methanol and $t$ butanol, only $14.8 \%$ of $t$-butanol gets converted. A twofold enhancement in methanol concentration increases the activity almost three times. Tenfold enhancement of methanol concentration increases the activity by eight times. Nonetheless, $100 \%$ selectivity to MTBE remains constant at all reactant ratios. The increase in activity with methanol concentration denotes the importance of solvent. High 
Table 11. Deactivation studies.

\begin{tabular}{lcc}
\hline Time on stream $(\mathrm{h})$ & Conversion $(\%)^{1}$ & Selectivity $(\%)^{2}$ \\
\hline 1 & 76.3 & 100 \\
2 & 93.5 & 100 \\
3 & 90.3 & 100 \\
4 & 89.3 & 100 \\
5 & 88.5 & 100 \\
6 & 87.0 & 100 \\
7 & 83.4 & 100 \\
8 & 83.8 & 100 \\
9 & 82.8 & 100 \\
\hline
\end{tabular}

Methanol/tert-butyl alcohol-10, Temperature- $180^{\circ} \mathrm{C}, \mathrm{WHSV}-$ $2.4 \mathrm{~h}^{-1}$.

${ }^{1}$ Total percentage of $t$-butyl alcohol transformed

${ }^{2}$ Selectivity to MTBE.

amounts of methanol suppress the conversion of $t$-butanol to isobutene. The decrease in activity at low methanol to $t$-butanol ratio can be attributed to high concentrations of $t$-butanol in the feed. The percentage conversion is calculated on the basis of $t$-butanol and high excess of it, increases the calculated conversions as expected.

Feed rate is another important parameter in vapour phase reactions. The influence of weight hourly space velocity on catalytic activity was checked by conducting reactions at four different space velocities. The results are tabulated in Table 11. From the table, it can be concluded that activity of catalyst increases with decrease in feed rate. Higher space velocities decrease the reaction rate. However, selectivity to MTBE remains the same irrespective of feed rate. Lower space velocity implies higher residence times for reactants in active sites and hence increased conversions. Increase in space velocity refers to insufficient contact time for reactants. This leads to speedy desorption of the reactant molecules from catalyst site before the completion of reaction and therefore lowered reaction rate.

Stability of the catalyst can be lost at increased durations of run. The performance of the reaction for a continuous $9 \mathrm{~h}$ run tests the susceptibility of catalyst. The products were collected and analysed at an interval of $1 \mathrm{~h}$. The results are tabulated in Table 12. From the table it is clear that activity declines steadily with time. Thus conversion \% that is 93.5 at the second hour, becomes 82.8 at the end of ninth hour. However, $100 \%$ selectivity towards MTBE remains the same throughout. The lowering of activity with time is a common problem associated with solid acids. Literature sug- gests that zeolites are more resistant to this effect. The resistance was attributed to the relatively small diffusion hindrance of these microporous catalysts and to their high hydrophobicity [25]. The prepared pillared clays have pore volumes much smaller than reported zeolites and hence difficulty in diffusion of the product due to pore blocking can be the reason for deactivation.

\section{Mechanism of the Reaction}

Over cation exchange resins, the reaction is considered to occur by intermediate formation of isobutene (IB). For TBA-methanol-acid ion exchange system, following three reactions can take place.

$$
\begin{aligned}
& \mathrm{TBA} \rightarrow \mathrm{IB}+\mathrm{H}_{2} \mathrm{O} \\
& \mathrm{IB}+\mathrm{MeOH} \rightarrow \mathrm{MTBE} \\
& \mathrm{TBA}+\mathrm{MeOH} \rightarrow \mathrm{MTBE}+\mathrm{H}_{2} \mathrm{O}
\end{aligned}
$$

If isobutene produced in the second reaction is consumed simultaneously and completely, then the reaction can be represented by the third equation. For cation exchange resins, Ancillotti et al. proposed that the reaction is catalysed mainly by solvated proton when methanol is present in large excess $[26,27]$. Thus, the reaction is quasi homogeneous or quasi heterogeneous depending on reactant concentrations. However, recent literature suggests an ionic mechanism for the reaction over solid acids. The reaction mechanism involves the formation of isobutyl carbonium ion intermediates followed by the nucleophilic attack of methanol molecules $[28,29]$. A similar mechanism can be envisaged in the present study also. Dependence of catalytic activity on acidity confirms the ionic mechanism.

\section{Conclusions}

The various points that can be summarised from the preceding discussion are,

- Chemical composition of prepared systems as determined by EDX analysis reveals that amount of pillared metal increases at the expense of exchangeable cations. $1-3 \%$ of the transition metals were incorporated on exchange.

- Surface area and pore volume increases substantially upon pillaring. $60-70 \%$ of the total surface area can be attributed to micropores. Transition metal 
exchange decreases the surface area, especially the external surface area.

- Presence of X-ray diffraction peaks shows that long range face to face layer aggregation is present in pillared sample. Shifting of $2 \theta$ values clearly suggest expansion of clay layer during pillaring process. Presence of $\mathrm{Fe}$ substituted $\mathrm{Al}_{13}$ like polymers are detected in the mixed pillared system. Insertion of the second metal after the formation of stable pillars does not destabilise the porous network.

- For iron pillared systems, ${ }^{27} \mathrm{Al}$ NMR peaks are broader due to the relaxation effects of the paramagnetic centres. The structure of iron aluminium mixed pillared systems is similar to Al polymeric species and not hydroxy iron oligomers. Incorporation of the transition metals does not affect the structural stability of the layers and pillars.

- ${ }^{29} \mathrm{Si}$ NMR spectra reveal that majority of the silicon tetrahedra is linked to $3 \mathrm{Si}$ atoms and one $\mathrm{Al}$ atom. A very small portion is linked to $2 \mathrm{Al}$ atoms and $2 \mathrm{Si}$ atoms while a part of the Si tetrahedra is linked to $\mathrm{Si}$ atoms alone. This distribution of silicon tetrahedra into various environments is not affected by pillaring. The shift in ppm, which indicates the strain in the local environment of the $\mathrm{Si}$ atoms, is proportional to the size of intercalated species. As anticipated, pillaring which is only a cation exchange process does not affect the short range order within the clay layers. Incorporation of transition metals on the pillared systems does not alter the local environment of the $\mathrm{Si}$ atoms.

- TPD profiles show the presence of weak (ammonia desorbed between $35-200^{\circ} \mathrm{C}$ ), medium (201$\left.400^{\circ} \mathrm{C}\right)$ and strong $\left(401-600^{\circ} \mathrm{C}\right)$ acid sites. All systems show considerable acidity. Weak and medium strength acid sites predominate the strong sites in all cases. Exchange with transition metals increases the amount of cumulative as well as strong acid sites. The increase in acidity, especially in the strong acidity region as a result of transition metal deposition is due to the increase in acidity of the pillars.

- Cumene cracking test reaction could differentiate between Lewis and Brönsted acid sites. Dehydrogenation activities could be well correlated with Lewis acidity as obtained from perylene adsorption studies

- Iron containing pillared clay catalysts are efficient catalysts for gas phase MTBE synthesis from methanol and $t$-butanol by direct method. Exclusive formation of MTBE was observed in all cases.
The activities could be well correlated with Brönsted acidities and/or the amount of weak and medium sites for iron and mixed pillared systems. The reaction variables like temperature, space velocity and molar ratio prove to be critical for the reaction. Deactivation of the catalyst occurs on longer durations of run. However selectivity to MTBE remains the same throughout.

\section{Acknowledgment}

Financial assistance from CSIR, New Delhi to K. Manju is gratefully acknowledged.

\section{References}

1. C.I. Warburton, Catal. Today. 2, 271-280 (1988).

2. K. Bahranowski, M. Gasior, A. Kielski, J. Podobinski, E.M. Serwicka, L.A. Vartikian, and K. Wodnicka, Clays. Clay Miner. 46, 98-102 (1998).

3. L. Bergaoui, J.F. Lambert, H. Suquet, and M. Che, J. Phy. Chem. 99, 2155 (1995).

4. J.G. Goodwin Jr., S. Natesakhawat, A.A. Nikolopoulos, and S.Y. Kim, Catal. Rev. Sci. Eng. 44, 287-320 (2002).

5. M.A. Ali, B.J. Bridson, and W.J. Thomas, Appl. Catal. A: Gen. 197, 303 (2000).

6. T. Horwath, M. Seiler, and M. Hunger, Appl. Catal. A: Gen. 193, 227 (2000).

7. J.S. Kim, J.M. Kim, G. Seo, N.C. Park, and S. Niiyama, Appl. Catal. 37, 45 (1988).

8. M.E. Quiroga, N.S. Figoli, and U.A. Sedran, J. Chem. Eng. 67, 199 (1997).

9. J.M. Adams, K. Martin, R.W. McCabe, and S. Murray, Clays. Clay Miner. 34, 597-603 (1986).

10. Z. Ziang, K. Hidajat, and A.K. Ray, J. Catal. 200, 209-221 (2001).

11. J.M. Adams, Appl. Clay Sci. 2, 309 (1987).

12. J.F. Knifton, US Patent 5,352,847 (1994).

13. D.W. Rutherford, C.T. Chiou, and D.D. Eberl, Clays.Clay Miner. 45, 534-543 (1997).

14. F. Bergaya, N. Hassoun, J. Barraoult, and L. Gatineau, Clay Miner. 28, 109 (1993).

15. D. Zhao, G. Wang, Y. Yang, X. Guo, Q. Wang, and J. Ren, Clays. Clay Miner. 41, 317 (1993).

16. L. Li, X. Liu, Y. Ge, R. Xu, J. Rocha, and J. Klinowski, J. Phy. Chem. 97, 10389-10393 (1993).

17. D. Plee, F. Borg, L. Gatineau, and J.J. Fripiat, J. Am. Chem. Soc. 107, 2362-2369 (1985).

18. M.R. SunKou, S. Mendioroz, and V. Munoz, Clays. Clay Miner. 48 528-536 (2000).

19. S.M. Bradley and R.A. Kydd, J. Catal. 141, 239 (1993).

20. H.M. Yuan, Z. Liu, and M. Enze, Catal. Today. 2, 321-338 (1988).

21. A. Aurox and A. Gervasini, J. Phy. Chem. 94, 6371 (1990). 
22. S. Moreno, R. SunKou, R. Molina, and G. Poncelet, J. Catal 182, 174-185 (1999).

23. A. Corma and B.W. Wojciechowski, Catal. Rev. Sci. Eng. 24, 1 (1982).

24. T. Sano, Y. Uno, Z.B. Zang, C.H. Ahn, and K. Soga, Microporous. Mesoporous Mater. 31, 89-95 (1999).

25. Q.H. Xia, K. Hidajat, and S. Kawi, J. Catal. 209, 433-444 (2002)
26. F. Ancillotti, M. Massi Mauri, and E. Pescarallo, J. Catal. 46, 49 (1977).

27. F. Ancillotti, M. Massi Mauri, E. Pescarallo, and L. Romagnoni, J. Mol. Catal. 4, 37 (1978).

28. G.J. Hutchings, C.P. Nicolaides, and M.S. Scurrell, Catal. Today, 15, 23 (1992).

29. van Le, R. Mao, T.S Le, M. Faibairn, A. Muntasar, S. Xiao, S. Denes, Appl. Catal. A: Gen. 185, 221 (1999). 